\section{POS0981 COMPUTED TOMOGRAPHY-BASED ASSESSMENT OF RADIOGRAPHIC PROGRESSION IN SPINE AND SACROILIAC JOINTS AFTER PREGNANCY IN WOMEN WITH ANKYLOSING SPONDYLITIS}

K. A. Lee ${ }^{1}$, S. Y. Lee ${ }^{2}$, H. S. Kim', H. R. Kim ${ }^{3}$, S. H. Lee ${ }^{2} .{ }^{1}$ Soonchunhyaung University Seoul Hospital, Internal Medicine, Seoul, Korea, Republic of (South Korea); ${ }^{2}$ Kyung Hee University Hospital at Gangdong, Internal Medicine, Seoul, Korea, Republic of (South Korea); ${ }^{3}$ Konkuk University Medical Center, Internal Medicine, Seoul, Korea, Republic of (South Korea)

Background: Mechanical stress are one of the pathogenesis of ankylosing spondlitis (AS). During pregnancy, the mechanical overload on the spine and pelvis increases due to gravid uterus. Recently, computed tomography syndesmophyte score (CTSS) has been developed to analysis of the spinal damage in patients with AS. Indeed, CT has higher sensitivity and reliability compared to conventional radiography in the detection of sacroilititis.

Objectives: We aimed to investigate whether pregnancy and delivery affect radiographic progression of spine and SIJ in women with AS based on CT evaluation. Methods: This retrospective study included women aged 19-49 years with AS who performed at least twice CT scans of whole-spine or sacroilliac joints (SIJ) at intervals of 2 to 4 years. To compare the radiographic progression after delivery, we classified into 2 groups: delivery group or controls. Delivery group was restricted to subjects who had the first CT scans $\sim 2$ years before delivery and the second CT scans $\sim 2$ years after delivery. CTSS (0-522) and SIJ scores (0-40) were used to evaluate the spinal syndesmophyte and erosion, joint space narrowing, and sclerosis of SIJ.

Results: A total of 21 women in delivery group and 38 women in controls were included. The median (Q1-Q3) CTSS at baseline in delivery group and controls were 19 (16-23) and 20 (13.25-27.75), and median progression was 1 (0-3) and 0 (0-1) during the median 2.9 year follow-up. The median (Q1-Q3) SIJ scores at baseline in delivery group and controls were 13 (8-22) and 11 (6-22), and median progression was $1.5(0-3)$ and $1(0-2)$. The CTSS and SIJ scores significantly increased in both groups, but no difference in absolute score changes per time point between was observed. The changes in SIJ scores was comparable according to the delivery methods.

Conclusion: This study suggests that pregnancy and delivery had no effect on radiographic progression of spine and SIJ in female with AS. REFERENCES:

[1] de Bruin F, de Koning A, van den Berg R, Baraliakos X, Braun J, Ramiro S. Development of the CT Syndesmophyte Score (CTSS) in patients with ankylosing spondylitis: data from the SIAS cohort. 2018;77(3):371-7.

Disclosure of Interests: None declared.

DOI: 10.1136/annrheumdis-2021-eular.2251

\section{POS0982 DIAGNOSTIC VALUE OF SPECT/CT IN AXIAL SPONDYLOARTHRITIS AND OTHER LOW BACK PAIN}

J. S. Kim ${ }^{1}$, K. Hyun-Sook', L. Kyung-Ann. . 'Soonchunhyang University Seoul Hospital, Soonchunhyang University College of Medicine, Internal Medicine, Seoul, Korea, Republic of (South Korea)

Background: Spondyloarthropathies (SpA) including ankylosing spondylitis are characterized by inflammatory arthritis involving the spine and peripheral joints. Bone SPECT/CT is in the spotlight as it can reflect the current level of inflammation.

Objectives: We aimed to investigate the diagnostic performance of bone SPECT/CT for axial SpA (axSpA) at the level of sacroiliac joints.

Methods: Patients with low back pain who had undergone SPECT/CT of the $\mathrm{SI}$ joints were selected for inclusion in this study through a retrospective review of medical records from August 2016 and July 2018. We used semi-quantitative scoring methods for SPECT/CT. For visual scoring, a score of 0 was assigned when tracer uptake in the sacroiliac joint was less than that in the sacrum; a score of 1 , when equal to that in the sacrum; and a score of 2 , when greater than that in the sacrum. A score of 2 was considered positive for the diagnosis of sacroiliitis on SPECT/CT (Figure 1). The diagnosis of axSpA was retained when patients fulfilled the Assessment of SpA International Society criteria.

Results: A total of 164 patients were enrolled (34 patients with axSpA) The remaining 130 patients had non-axSpA rheumatic inflammatory disease $(n=24)$, vertebral disk herniation $(n=13)$, avascular necrosis $(n=11)$ and others such as bursitis, and fracture $(n=85)$. The mean age of aSpA (37.8 \pm 15.6 years) was lower than controls $(49.8 \pm 16.4$ years $)(p<0.001)$, and axSpA $(64.5 \%)$ had more male than others $(42.1 \%)(p=0.024)$. The sensitivity, specificity, positive and negative predictive values of bone SPECT/ CT for axSpA were $83.9 \%, 63.2 \%, 34.7 \%$, and $94.4 \%$, respectively. The bone SPECT/CT maximal score and BASDAI score has positive correlation $(r=0.481, p=0.007)$. The bone SPECT/CT compared with MRI is marginal correlation $(\mathrm{k}=0.369, p<0.001)$.
Conclusion: In patients with low back pain, the bone SPECT/CT has a high negative predictive value that can exclude AS. In addition, when contraindication in MRI the bone SPECT/CT can be an alternative test.

\section{REFERENCES:}

[1] Rahul V. Parghane, Baljinder Singh, Aman Sharma, Harmandeep Singh Paramjeet Singh, and Anish Bhattacharya. Role of $99 \mathrm{mTc}$-Methylene Diphosphonate SPECT/CT in the Detection of Sacroilitis in Patients with Spondyloarthropathy: Comparison with Clinical Markers and MRI. J NuCl Med Technol 2017; 45:280-28

[2] Anuj Jain, Suruchi Jain, w A n I I A g a r w a I, Sanjay Gambhir, Chetna Shamshery, and Amita Agarwal(2015). Evaluation of Efficacy of Bone Scan With SPECT/CT in the Management of Low Back Pain. A Study Supported by Differential Diagnostic Local Anesthetic Blocks. Clin J Pain 2015;31:1054-1059

[3] Yong-il Kim, Minseok Suh, Yu Kyeong Kim, Ho-Young Lee and Kichul Shin The usefulness of bone SPECT/CT imaging with volume of interest analysis in early axial spondyloarthritis. BMC Musculoskeletal Disorders (2015) 16:9

[4] Jennifer Saunders, Mel Cusi, and Hans Van der Wall. What's Old Is New Again: The Sacroiliac Joint as a Cause of Lateralizing Low Back Pain. Tomography (2018) VOLUME 4 NUMBER 2

[5] Satoshi Kato, Satoru Demura, Hidenori Matsubara, Anri Inak2, Kazuya Shinmura, Noriaki Yokogawa, Hideki Murakam1, Seigo Kinuya and Hiroyuki Tsuchiya. Utility of bone SPECT/CT to identify the primary cause of pain in elderly patients with degenerative lumbar spine disease. Journal of Orthopaedic Surgery and Research (2019) 14:185

[6] Romain De Laroche, Erwan Simon, Nicolas Suignard, Thomas Williams, Marc-Pierre Henry, Philippe Robin, Ronan Abgral, David Bourhis Pierre-Yves Salaun, Frédéric Dubrana, Solène Querellou. Clinical interest of quantitative bone SPECT-CT in the preoperative assessment of knee osteoarthritis. De Laroche et al. Medicine (2018) 97:35

[7] Inki Lee, Hendra Budiawan, Jee Youn Moon, Gi Jeong Cheon, Yong Chu Kim, Jin Chul Paeng, Keon Wook Kang, June-Key Chung, and Dong Soo Lee. The Value of SPECT/CT in Localizing Pain Site and Prediction of Treatment Response in Patients with Chronic Low Back Pain. J Korean Med Sci 2014; 29: 1711-1716

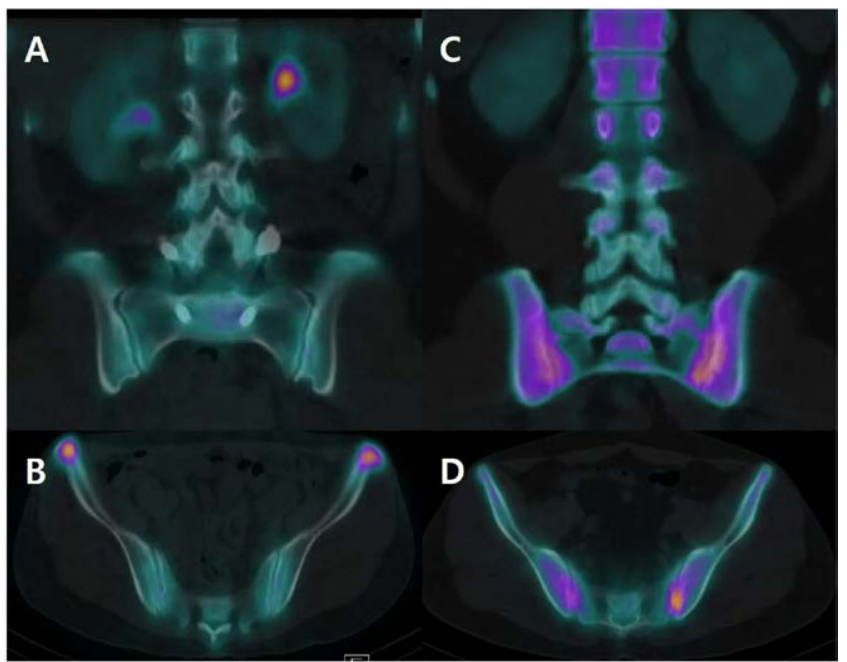

Figure 1. There is two bone SPECT/CT imaging. (A,B) 44 years old female diagnosed with ankylosing spondyliti AS) and her Bath Ankylosing Spondylitis Disease Activity Index (BASDAI) score is 2.2. For visual scoring is I sacritinc joint uptake is greater than the sacrum, so semi-quantitative scoring is 2 .

Disclosure of Interests: None declared.

DOI: 10.1136/annrheumdis-2021-eular.2296

\section{\begin{tabular}{|l|l|l|}
\hline POS0983 WORK PARTICIPATION IN PATIENTS WITH AXIAL \\
\hline
\end{tabular} SPONDYLOARTHRITIS IN GERMANY: RESULTS FROM A MULTICENTER, OBSERVATIONAL SURVEY (ATTENTUS-AXSPA)}

U. Kiltz' ${ }^{1}$ K. Hoeper ${ }^{2}$, L. Hammel ${ }^{3}$, S. Lieb ${ }^{4}$, A. Haehle ${ }^{4}$, D. MeyerOlson ${ }^{5}$ on behalf of The study was sponsored by Novartis Pharma GmbH, Germany.. ${ }^{1}$ Rheumazentrum Ruhrgebiet; Ruhr Universität, Department of Rheumatology, Herne, Bochum, Germany; ${ }^{2}$ Regionales Kooperatives Rheumazentrum Niedersachsen e. V.; Medizinische Hochschule Hannover, Klinik für Rheumatologie und Immunologie, Department of Rheumatology, Hannover, Germany; ${ }^{3}$ Deutsche Vereinigung Morbus Bechterew e. V., Patient representative, Schweinfurt, Germany; ${ }^{4}$ Novartis Pharma GmbH, Immunology, Hepatology and Dermatology, Nürnberg, Germany; ${ }^{5}$ Medizinische Hochschule Hannover, Klinik für Rheumatologie und Immunologie; m\&i Fachklinik Bad 